\title{
Application of the Extended Grunwald-Winstein Equation to Solvolyses of n-Propyl Fluoroformate and a Consideration of Leaving Group Effects
}

\author{
Mi Hye Seong, Jin Burm Kyong, "Dong Kook Kim, and Dennis N. Kevill’ \\ Deparment of Chemistry and Applied Chemistry Hanvang Lniversity, Ansan, Gyeonggi 426-791, Korea \\ E-mail: jbkvongahanting.ac.kr \\ -Department of Chemistry and Biochemistr, Northem Mhinois Cniversitw, DeKalb, Ilinois 60115-2862, U.S.A. \\ Received July 12, 2008
}

\begin{abstract}
Reactions of $n$-propyl fluoroformate in a variety of pure and binany solvents have been studied at $40.0^{\circ} \mathrm{C}$. The extended (two-term) Grunwald-Winstein equation has been applied to the specific rates of solvoly sis of $n$ propyl fluoroformate. The sensitivities ( $/=1.80 \pm 0.17$ and $m=0.96 \pm 0.10$ ) to changes in solvent nucleophilicity and solvent ionizing power and the $k_{\mathrm{F}} / k_{\mathrm{cl}}$ values are similar to those for solvolyses of $n$-octyl fluorofonnate over the full range of solvents. suggesting that the addition step of an addition-elimination mechanism is ratedetermining. These observations are also compared with those previously reported for the corresponding chloroformate and fluoroformate esters.
\end{abstract}

Key Words : $n$-Propyl fluoroformate. Addition-elimination, Grumwald-Winstein equation. Leaving groupeffect

\section{Introduction}

Recently. the solvolyses of $n$-propyl chloroformate ${ }^{l}$ in a variety of pure and binary solvents were found to involve the reaction following the addition-elimination pathway in the majority of the solvents but an ionization pathway in the solvents of highest ionizing power and lowest nucleophilicity: For solvolyses of 1-adamantyl chloroformate." the ionization pathway was dominant in all solvents and only in $100 \%$ ethanol was a trace of the mixed carbonate observed. However. replacement of chlorine by fluorine (1-adamantyl fluoroformate ${ }^{3}$ ) led to behavior very similar to that previously observed for the solvolyses of $n$-propyl chloroformate. which have been shown to solvolyze with the addition step of an addition-elimination pathway in all solvents but the most ionizing and weakly mucleophilic solvents. For the bimolecular hydrolyses of a pair of fluorofomate and chloroformate esters, ${ }^{+}$the addition step was believed to be rate detemining. largely on the basis of the similar rates for the two halogenoformate esters. despite the stronger carbonfluorine bond. Particularly, the comparison of leaving group effects $\left(k_{\mathrm{H}} / k_{\mathrm{C}}\right.$ ratios) on the rates of solvolysis of chloroformate and fluorofonmate esters has provided useful information about the reaction mechanism. Similar ratios of $\mathrm{k}_{\mathrm{F}} / \mathrm{k}_{\mathrm{Cl}}$ specific rates have been observed previously for the solvolyses of other halofomate esters. ${ }^{5-8}$ For example. $k_{\mathrm{F}} / k_{\mathrm{cl}}$ ratios of 1.09 to 7.16 for $70 \%$ aqueous acetone at $30.1{ }^{\circ} \mathrm{C}$. have been reported ${ }^{4}$ For solvolyses. the two proposed nucleophilic substitution mechanisms can be expressed as an addition-elimination mechanism (Scheme 1) and as an ionization mechanism (Scheme 2).

The extended Grunwald-Winstein (equation (1)) can be applied as a powerful mechanistic tool. ${ }^{\text {s. }}$.

$$
\log \left(k / k_{o}\right)=I N_{\mathrm{T}}-m Y_{\mathrm{X}}+c
$$

In equation (1), $k$ and $k_{o}$ are the specific rates of solvoly sis

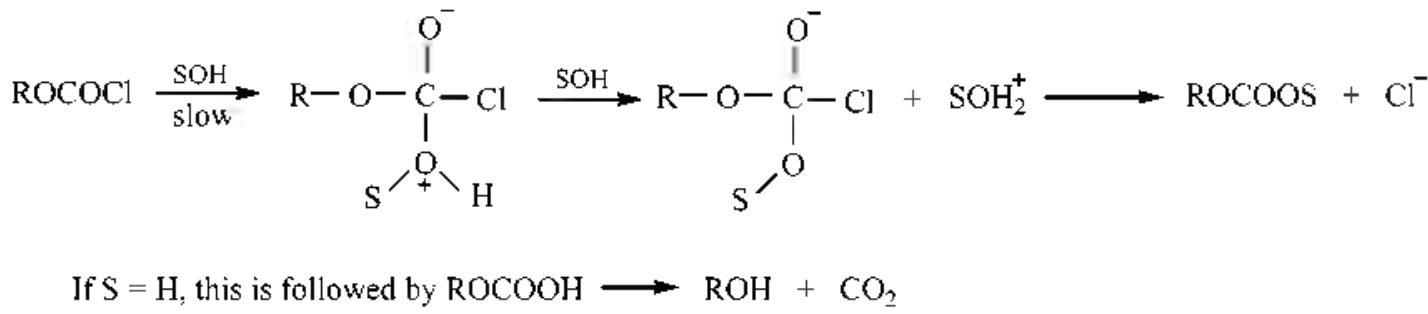

Scheme 1

$$
\mathrm{ROCOCl} \underset{\text { slow }}{\longrightarrow}[\mathrm{R}-\mathrm{O}-\stackrel{+}{\mathrm{C}}=\mathrm{O} \leftrightarrow \mathrm{R}-\stackrel{+}{\mathrm{O}}=\mathrm{C}=\mathrm{O}] \mathrm{Cl}^{-} \stackrel{-\mathrm{CO}_{2}}{\text { fast }} \mathrm{R}^{+} \mathrm{Cl}^{-} \underset{\mathrm{H}_{2} \mathrm{O}}{\stackrel{\mathrm{SOH}}{\longrightarrow}} \mathrm{ROS}
$$


of a substrate RX in a given solvent and in the standard solvent $(80 \%$ ethanol), respectively; $l$ is the sensitivity toward changes in solvent nucleoplilicity $N_{\mathrm{T}}:^{\left.1 i_{1}\right] 1} \mathrm{~m}$ is the sensitivity toward changes in solvent ionizing power $Y_{X}:^{12.13}$ $c$ is a constant (residual) tern. Scales of solvent nucleophilicity and of solvent ionizing power are available and, by measuring $k$ and $k_{0}$. one can carry out a mathematical analysis to obtain the $I$ and $m$ values. For an ionization reaction without nucleophilic assistance. $/$ will be zero and $m$ close to unity. Accordingly. determination of the $l$ and $m$-values will be a valuable source of information concerning the structure of the transition state for these solvolyses.

In this work, we deternine the overall specific rates for solvoly ses of $n$-propyl fluoroformate in a variety of pure and binary solvents. The solvolyses of several chloroformate esters divided. in the usually studied solvents. into two almost equally sized groups, with either ionization or additionelimination as the rate-deternining step. ${ }^{14}$ Mechanistic conclusions are then drawn from a consideration of the analyses using the extended Grumwald-Winstein equation. including a comparison with the $/$ and $m$ values determined from a combination of published and new kinetic data for solvolyses of n-propyl fluoroformate. In addition to an extended GrunwaldWinstein equation of the specific rates, these analyses are combined with a consideration of leaving group effects to arrive at a reasonable mechanism.

\section{Materials and Methods}

Materials. The $n$-propyl chloroformate (Aldrich) was purified by fractional distillation at reduced pressure. The $n$ propyl chloroformate $(5.0 \mathrm{~g} .0 .04 \mathrm{l} \mathrm{mol})$ was syringed into a three-neck flask $(250 \mathrm{~mL}$ ) containing dried KF (3.45 g. $0.059 \mathrm{~mol})$ and $18-c r o w n-6(0.42 \mathrm{~g} .0 .0016 \mathrm{~mol})$ and fitted with a Teflon stiring bar, a condenser topped by an $\mathrm{N}_{2}$ gas inlet. a septum cap, and a ground glass stopper. as described earlier. ${ }^{15}$ The mixture then was stirred efficiently at room temperature until FT-IR (Bio-Red FTS 6000) analysis of an aliquot indicated that no chloroformate remained $(\mathrm{C}=\mathrm{O}$ stretch at $1752 \mathrm{~cm}^{-1}$ : fluoroformate $\mathrm{C}=\mathrm{O}$ stretch at 1830 $\mathrm{cm}^{-1}$ ). After a reaction time of 45 hours, the $n$-propyl fluoroformate was isolated directly from the reaction apparatus by simple distillation at a reaction temperature of $91-93^{\circ} \mathrm{C}$. The solvents were purified as previously described. ${ }^{\mathrm{s}}$

Methods. The kinetic runs were carried out as previously described. 816 The rates of production of hydrofluoric acid were followed for solvolyses in methanol. ethanol, aqueousorganic mixtures. and TFE-ethanol mixtures. Portions were removed at appropriate time intervals and partitioned between $20 \mathrm{~mL}$ of pentane and $10 \mathrm{~mL}$ of degassed distilled water. The acid previously developed was then titrated against a standardized solution of $\mathrm{NaOH}$ in water ( $c a .5 .00 \times$ $10^{-3} \mathrm{M}$ ) to a methylene blue-nethyl red endpoint. ${ }^{16}$ Runs in 2.2.2-trifluoroethanol (TFE) $-\mathrm{H}_{2} \mathrm{O}$ solvents and in TFE$\mathrm{EtOH}$ solvents involved removal of $2 \mathrm{~mL}$ portions from 25 $\mathrm{mL}$. and nuns in 1.1.1.3.3.3-hexafluoro-2-propanol (HFIP)$\mathrm{H}_{2} \mathrm{O}$ solvents involved removal of $1 \mathrm{~mL}$ portions from 10
$\mathrm{mL}$, and runs in other solvents involved removal of $5 \mathrm{~mL}$ portions from $50 \mathrm{~mL}$. The substrate concentration was about $5.00 \times 10^{-3} \mathrm{M}$. Experimental infinity titers were obtained after at least ten half-lives and the deteminations of the firstorder rate coefficients (specific rates) of solvolysis were calculated from the equation (2). In equation (2), $V_{\circ}$ is the titer at time zero (when first portion is removed), $V_{t}$ is the titer at time ( $t$ ) of removal of a subsequent portion, and $V_{*}$ is the titer for a portion removed after at least ten half-lives. The $/$ and $m$ values were calculated using commercially available computer programs for multiple regression analyses.

$$
k=\frac{1}{t} \ln \frac{\left(V_{\infty}-V_{0}\right)}{\left(V_{\infty}-V_{i}\right)}
$$

\section{Results and Discussion}

The specific rates of solvolysis of $n$-propyl fluoroformate were determined in 20 solvents at $40.0^{\circ} \mathrm{C}$. The solvents consisted of ethanol. methanol binary mixtures of water with ethanol $(\mathrm{EtOH})$. methanol $(\mathrm{MeOH})$, acetone $\left(\mathrm{Me}_{2} \mathrm{CO}\right)$. TFE, or HFIP, and four binary mixtures of TFE and ethanol (T-E). The specific rates of solvolysis are presented in Table 1. together with $N_{\mathrm{T}}$ and $Y_{\mathrm{Cl}}$ values. Specific rates of solvoly sis of $n$-propyl chloroformate were determined in six solvents at the same temperature. These values are reported in Table 2. together with the $k_{\mathrm{F}} / k_{\mathrm{C}]}$ ratios

An analysis of the 19 specific rates of Table 1 leads. in

Table 1. Specific rates of solvolysis of $n$-propyl fluoroformate in at variety of pure and mixed solvents at $40.0{ }^{\circ} \mathrm{C}$ and the $\mathrm{N}_{\mathrm{T}}$ and $\mathrm{F}_{\mathrm{Cl}}$ values for the solvents

\begin{tabular}{|c|c|c|c|}
\hline Solvent ${ }^{\prime \prime}$ & $10^{4} k\left(\mathrm{~s}^{-1}\right)$ & $\mathrm{N}_{\mathrm{T}}^{b}$ & $I_{C l}$ \\
\hline $100 \% \mathrm{MeOH}$ & $2.19 \pm 0.04^{d}$ & 0.17 & -1.17 \\
\hline $90 \% \mathrm{MeOH}$ & $18.8 \pm 0.4$ & -0.01 & -0.18 \\
\hline $80 \% \mathrm{MeOH}$ & $37.4 \pm 2.0$ & -0.06 & 0.67 \\
\hline $100 \% \mathrm{EtOH}$ & $0.437 \pm 0.020$ & 0.37 & -2.52 \\
\hline $90 \% \mathrm{EtOH}$ & $6.79 \pm 0.15$ & 0.16 & -0.94 \\
\hline $80 \% \mathrm{EtOH}$ & $14.0 \pm 0.5$ & 0.00 & 0.00 \\
\hline $70 \% \mathrm{EtOH}$ & $23.7 \pm 0.5$ & -0.20 & 0.78 \\
\hline $80 \% \mathrm{Me}_{2} \mathrm{CO}$ & $0.785 \pm 0.047$ & -0.37 & -0.83 \\
\hline $70 \% \mathrm{Me}_{2} \mathrm{CO}$ & $2.58 \pm 0.16$ & -0.42 & 0.17 \\
\hline $90 \% \mathrm{TFE}$ & $0.123 \pm 0.021$ & -2.55 & 2.85 \\
\hline $70 \% \mathrm{TFE}$ & $2.20 \pm 0.06$ & -1.98 & 2.96 \\
\hline $50 \% \mathrm{TFE}$ & $10.8 \pm 0.7$ & -1.73 & 3.16 \\
\hline $80 \mathrm{~T}-20 \mathrm{E}^{e}$ & $0.144 \pm 0.024$ & -1.76 & 1.89 \\
\hline $60 \mathrm{~T} 40 \mathrm{E}^{e}$ & $0.321 \pm 0.055$ & -0.94 & 0.63 \\
\hline $40 \mathrm{~T}-60 \mathrm{E}^{e}$ & $0.532 \pm 0.024$ & -0.34 & -0.48 \\
\hline $20 \mathrm{~T}-80 \mathrm{E}^{e}$ & $0.926 \pm 0.051$ & 0.08 & -1.42 \\
\hline $90 \%$ HFIP & $0.0213 \pm 0.0010$ & -3.84 & 4.31 \\
\hline $70 \%$ HFIP & $0.761 \pm 0.032$ & -2.94 & 3.83 \\
\hline $50 \%$ HFIP & $7.00 \pm 0.36$ & -2.49 & 3.80 \\
\hline
\end{tabular}

"Volume volume basis at $25.0^{\circ} \mathrm{C}$, except for TFE- $\mathrm{H}_{2} \mathrm{O}$, HFIP- $\mathrm{H}_{2} \mathrm{O}$ mixtures, which are on a weightweight basis. "Values from refs. 10.11 . 'Values from refs. 12.13 Value in $\mathrm{CH}_{3} \mathrm{OD}$ of $(0.659 \pm 0.020) 10^{-4}$ $\mathrm{sec}^{-1}$, and solvent deuterium isotope effect ( $h_{\mathrm{MeOH}} \bar{k}_{\mathrm{MeOI}}$ ) of 3.32. "T-E are 2.2.2-trifluoroethanol-ethanol mistures. 
Table 2. Specific rates of the solvoly ses of $n$-propyl chlorofonmate in a variety of pure and mixed solvents at $40.0^{\circ} \mathrm{C}$ and $k_{\mathrm{F}} / k_{\mathrm{Cl}}$ specific rate ratios

\begin{tabular}{ccc}
\hline Solvent $^{t i}$ & $10^{5} k_{\mathrm{Pr} O \mathrm{Col}} \mathrm{s}^{-1}$ & $k_{\text {Proco }} / k_{\text {Prococ }}{ }^{b}$ \\
\hline $100 \% \mathrm{EtOH}$ & $7.73 \pm 0.02$ & 0.57 \\
$80 \% \mathrm{EtOH}$ & $24.9 \pm 0.3$ & 5.62 \\
$100 \% \mathrm{MeOH}$ & $29.4 \pm 0.6$ & 0.75 \\
$70 \% \mathrm{Me}_{2} \mathrm{CO}$ & $6.09 \pm 0.01$ & 4.24 \\
$70 \% \mathrm{TFE}$ & $2.85 \pm 0.02$ & 7.72 \\
$70 \% \mathrm{HFIP}$ & $2.77 \pm 0.03$ & 2.75 \\
\hline
\end{tabular}

"Volume solune basis at 25.0 "C. except for TFE- $\mathrm{H}_{2} \mathrm{O}$. HFIP- $\mathrm{H}_{2} \mathrm{O}$ mixtures. which are on a weight weight basis. "Specific rates of solvolysis of 7)-propyl fluoroformate are from Table 1.

terms of the simple Grunwald-Winstein equation [equation (1) without the $\mathrm{N}_{\mathrm{T}}$ term]. to a very poor correlation with value 0.208 for the correlation coefficient. An analysis of the data obtained by applying the modified form of the Grunvald-Winstein equation [eqn. (1)] to the specific rates of solvolysis of $n$-propyl fluoroformate leads to an acceptable linear correlation with values of $1.80 \pm 0.17$ for $/ .0 .96 \pm$ 0.10 for $m .-0.01 \pm 0.1$ for $c$. The correlation coefficient (r) is still rather low at 0.940 and the F-test value is 60 . Inspection of the plot corresponding to this correlation (Figure 1) shows that three binary mixtures of TFE and ethanol (80T-20E. 60T-40E. and 40T-60E mixtures) lie below the best fit line. In earlier correlations of other haloformate esters. it was found that the data points for TFEethanol solvent systems usually lie below the correlation line. ${ }^{17.15}$ This phenomenon was very recently discussed and it will not be considered again in this paper ${ }^{3 i j}$ When these data points are omitted from the correlation. the $/$ and $m$ values are only slightly reduced but considerably improved values for the correlation coefficient $(r=0.970)$ and for the F-test value $($ F-test $=104)$ are observed (Figure 2 and Table

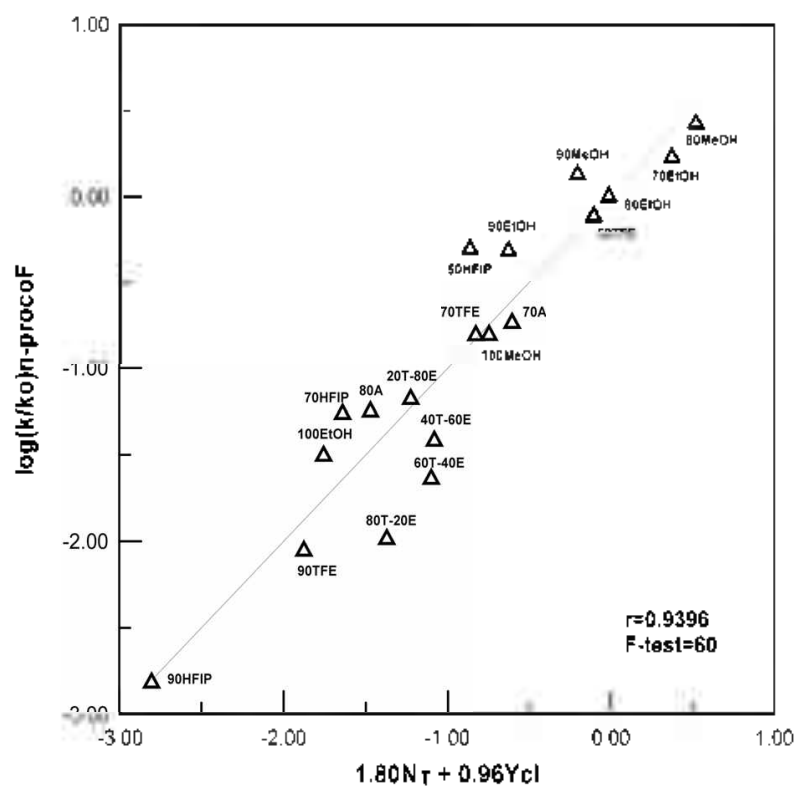

Figure 1. Plot of $\log \left(k / k_{0}\right)$ for solvoly ses of $n$-propyl fluorofonmate in pure and binary solvents at $40.0^{\circ} \mathrm{C}$ against $\left(1.80 \mathrm{~V}_{\mathrm{T}}+0.96 \mathrm{~F}_{\mathrm{C}}\right)$.

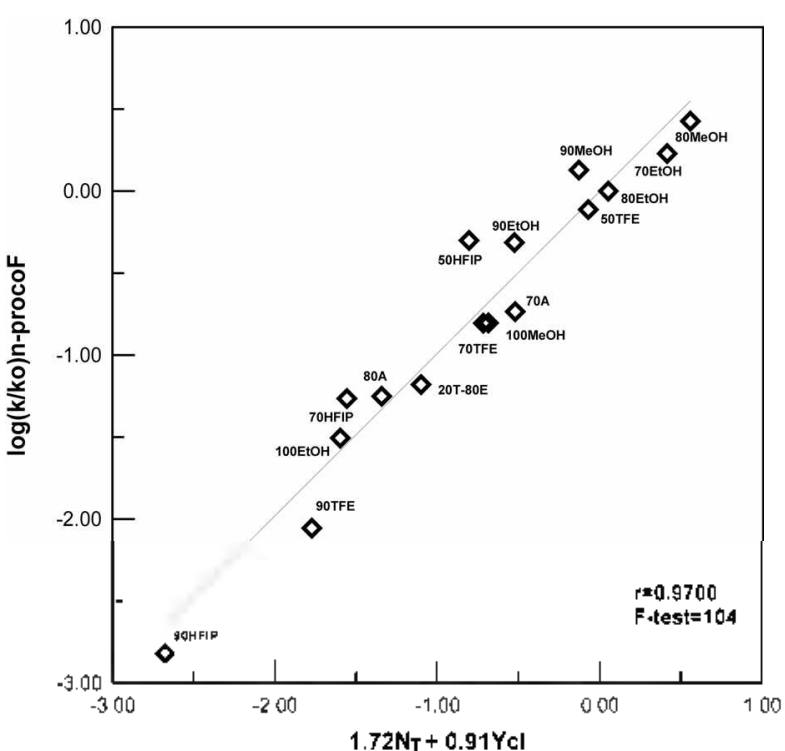

Figure 2. Plot of $\log \left(k / k_{0}\right)$ for solvoly ses of $n$-propyl fluorotomate in pure and binary solvents at $40.0^{\circ} \mathrm{C}$ against $\left(1.72 \mathrm{~K}_{\mathrm{T}}+0.91 \mathrm{Y} \mathrm{C}\right)$. with omission of the three data points for $80 \mathrm{~T}-20 \mathrm{E}, 60 \mathrm{~T}-40 \mathrm{E}$, and 40T-60E.

3). The the correlation is presented in Figure 1 and included in Table 3. together with the corresponding parameters obtained for earlier studied substrates. The $/$ and $m$ values for the solvolysis of $n$-propyl fluoroformate, respectively, were similar to values previously reported for bimolecular solvolyses of other chloroformate and fluoroformate esters, believed to solvolyze by an addition-elimination mechanism. with the addition being rate-determining. An LFER plot of $\log \left(k / k_{0}\right)$ for $n$-propyl fluoroformate against $\log \left(k / k_{0}\right)$ for n-octyl fluoroformate shows a good linear correlation ( $\mathrm{r}$ $=0.985$ ) in pure and mixed solvents. giving a strong evidence for a similar solvoly sis mechanism.

The specific rate ratios $\left(k_{\mathrm{F}} / k_{\mathrm{Cl}}\right)$ of solvolysis of $n$-propyl fluoroformate and chloroformate show with values ranging from 0.57 in ethanol to 7.72 in $70 \%$ TFE (Table 2). A recent report conceming the solvolyses of $n$-octyl fluoroformate and chloroformate found the $k_{\mathrm{F}} / k_{\mathrm{Cl}}$ ratio to be somewhat below unity in ethanol and methanol and to be slightly greater than unity for solvolyses in mixtures of water with ethanol, acetone or TFE. ${ }^{7}$ As mentioned above, for binary solvents, the fluorofomate is somewhat faster, despite the stronger carbon-fluorine bond. Since the carbon-fluoride bond is much stronger than the carbon-chloride bond. if the carbon-halogen bond is broken in the rate-determining. $k_{\mathrm{F}} / k_{(\mathrm{l})}$ ratios would be expected to exhibit a marked leaving group effect, $k_{\mathrm{F}} \ll k_{\mathrm{Cl}}$. However. bimolecular pathway through a tetrahedral intermediate formed by rate-determining addition of the solvent at the carbonyl carbon would be characterized by $k_{\mathrm{F}} \geq k_{\mathrm{Cl}}$.

The consideration of $k_{\mathrm{F}} / k_{\mathrm{Cl}}$ ratios in nucleophilic substitution reactions has long been recognized as a useful tool in studying the reaction mechanism..$^{21}$ This is especially so when the attack is at an acyl carbon. When the carbonhalogen bond is broken in a nucleoplilic displacement reac- 
Table 3. Correlation of the specific rates of solvolysis of n-propyl fluoroformate and a comparison with corresponding values for the solvolvses of other chloroformate and fluoroformate esters using the extended Grunwald-Winstein ${ }^{n}$

\begin{tabular}{|c|c|c|c|c|c|c|c|}
\hline Substrate & Mech. $^{b}$ & $n^{c}$ & $k^{l i}$ & $m^{d}$ & $c^{a^{l}}$ & $\overline{R^{e}}$ & $l / m$ \\
\hline PhOCOCl & A-E & $21^{f}$ & $1.68 \pm 0.10$ & $0.57 \pm 0.06$ & $0.12 \pm 0.41$ & 0.973 & 2.95 \\
\hline n-PTOCOCl & $A-E$ & $22^{\circ}$ & $1.57 \pm 0.12$ & $0.56 \pm 0.06$ & $0.15 \pm 0.08$ & 0.947 & 2.79 \\
\hline n-PTOCOCl & I & $6^{8}$ & $0.40 \pm 0.12$ & $0.64 \pm 0.13$ & $-2.45 \pm 0.47$ & 0.942 & 0.63 \\
\hline n-PrOCOF & $A-E$ & $19^{\prime \prime}$ & $1.80 \pm 0.17$ & $0.96 \pm 0.10$ & $-0.01 \pm 0.11$ & 0.940 & 1.88 \\
\hline n-PrOCOF & $A-E$ & $16^{\prime t}$ & $1.72 \pm 0.12$ & $0.91 \pm 0.08$ & $0.05 \pm 0.08$ & 0.970 & 1.89 \\
\hline$i-\mathrm{PrOCOCl}$ & I & $20^{s}$ & $0.28 \pm 0.05$ & $0.52 \pm 0.03$ & $-0.12 \pm 0.05$ & 0.979 & 0.54 \\
\hline$i-\mathrm{PTOCOF}$ & $A-E$ & 20 & $1.59 \pm 0.16$ & $0.80 \pm 0.06$ & $0.06 \pm 0.08$ & 0.957 & 1.99 \\
\hline OctoCOF & $A-E$ & $23^{k}$ & $1.80 \pm 0.13$ & $0.79 \pm 0.06$ & $0.13 \pm 0.34$ & 0.959 & 2.28 \\
\hline $\mathrm{C}_{n} \mathrm{H}_{s} \mathrm{COF}$ & $A-E$ & $41^{I}$ & $1.58 \pm 0.09$ & $0.82 \pm 0.05$ & $-0.09 \pm 0.10$ & 0.953 & 1.93 \\
\hline 1-AdOCOCl & I & $15^{m}$ & $-1)$ & $0.47 \pm 0.03$ & $0.03 \pm 0.05$ & 0.985 & $\leadsto$ \\
\hline
\end{tabular}

"Using equation $1 .{ }^{b}$ Addition-elimination (A-E) and ionization (I). "Number of solvent systems included in the correlation. ${ }^{d}$ Using equation $\mathrm{l}$, with standard errors for $/$ and $m$ Falues and with the standard errors of the estimate accompanying the $c$ value. ${ }^{\circ} \mathrm{Correlation}$ coefticient. ${ }^{/}$Values from ref. 19 . 5 Values from ref. 1 and the solvent systems divided into $100^{\circ}$, TFE. $97^{\circ} .0$ TFE, and all $\mathrm{HFIP}_{2} \mathrm{H}_{2} \mathrm{O}$ mistures ( three TFE-EtOH solvents $(n=17)$, 'Values from ref. 28 . Walues from ref. 25 . "Values from ref. 7 . "Values from ref. $24 .{ }^{n}$ Values from ref. 2.

tion, the specific rates of fluoro-derivative react appreciably slower than that for chloro-derivative. For some examples of $\mathrm{S}: 1$ reaction, a value as low as the $k_{\mathrm{F}} / k_{\mathrm{C}}$ rate ratio. $10^{-7}$ was observed in 4-(N,N-dimethylamino)benzoyl halide solvolyses ${ }^{33}$ and a low value of $1.3 \times 10^{-4}$ was also observed for acetyl halide solvolyses in $75 \%$ acetone ${ }^{21}$ These values reflect an appreciable ground-state stabilization for the fluoride ${ }^{23}$ and the need to break a strong carbon-fluorine bond in the rate determining step. In contrast, if the addition step is rate-determining, values of close to unity (and frequently above it). reflecting a large electron deficiency at the carbonyl carbon of a haloformate incorporating fluorine, ${ }^{\text {,- }}$ are frequently observed. For a meaningful comparison of the specific rates $\left(k_{\mathrm{F}} / k_{\mathrm{Cl}}\right)$ of solvolysis of $n$-propyl fluoroformate and chloroformate at $40.0^{\circ} \mathrm{C}$ in Table 2 , it is inportant that the comparison is for the same reaction pathway. The ratios vary from a low of 0.57 in ethanol $(0.60$ for $n$-octyl haloformate in ethanol $\left.{ }^{7}\right)$ to a high of 7.72 in $70 \%$ TFE ( 10.2 for $n$-octyl haloformate in $80 \% \mathrm{TFE}^{7}$ ). The $k_{\mathrm{F}} / k_{\mathrm{Cl}}$ specific rate ratios for a variety of pure and mixed solvents (Table 2) are similar to the values for reaction of $n$-octyl haloformate which has been shown to solvolyze by the bimolecular addition-elimination mechanism. proceeding through a tetrahedral intermediate.

The values of Table 3 divide into two principal mechanismus. i.e.. the so-called bimolecular mechanism postulated to represent addition-elimination pathway (Scheme 1) and unimolecular mechanism believed to represent ionization pathway (Scheme 2). For n-propyl fluoroformate. the value for the ratio $(l / m)$ of 1.89 is very similar to those previously observed for the solvolyses of $i$-propyl fluoroformate ${ }^{5} n$ octyl fluoroformate ${ }^{7}$ and benzoyl fluoride. ${ }^{-7}$ which have been shown to solvolyze with the addition step of an additionelimination pathway being rate determining. The higher $m$ values for the solvolyses of fluoroformates. relative to chloroformates. may reflect the need for increased solvation of the developing negative charge on the carbonyl oxygen in the presence of the more electronegative fluorine attached at the carbonyl carbon.
For methanolysis of $n$-propyl fluoroformate, the kinetic solvent isotope effect (KSIE) value using methanol- $d$ was presented in footnote to Table 1 . The $k_{\mathrm{MeOH}} / k_{\mathrm{MeOD}}$ value of 3.32 for n-propyl fluoroformate is higher than for the methanoly sis of $n$-propyl chloroformate $\left(k_{\mathrm{MeOH}} / k_{\mathrm{MeOD}}=2.17\right)^{1}$ or for the ethanolysis of a series of para-substituted phenyl chloroformates. where values in the range of 2.1-2.4 were obtained. ${ }^{26.27}$ The higher value gives further support for the proposal that bond formation is more advanced at the transition state for addition to fluoroformates than for chloroformates.

\section{Conclusions}

The specific rates of solvolyses of $n$-propyl fluoroformate give a satisfactory extended Grunwald-Winstein correlation (equation 1) over the full range of solvents. The $/$ and $m$ parameters obtained from the extended Grunwald-Wustein treatment of the specific rates of solvolyses of $n$-propyl fluoroformate are very similar to those previously obtained for the several fluoroformate and chloroformate esters (Table 3).

The $k_{\mathrm{F}} / k_{\mathrm{Cl}}$ values obtained in a comparison with the corresponding solvolysis of $n$-propyl chloroformate are similar to those for solvolyses of $i$-propyl haloformate. ${ }^{25}$ n-octyl haloformate and benzoyl halide..$^{-4}$ consistent with a bimolecular addition-elimination mechanism. proceeding through a tetrahedral internediate. Favoring an explanation in terms of alkyl variation is the observation that the $k_{\mathrm{F}} / k_{\mathrm{Cl}}$ ratio for solvolyses of haloformate esters in $70 \%$ acetone at $30.1^{\circ} \mathrm{C}$ decreases from methyl $(7.16),{ }^{4}$ ethyl $(5.46)^{4}$ or $n$-propyl (the $k_{\mathrm{F}} / k_{\mathrm{C}]}$ ratio of $n$-propyl group in $70 \%$ acetone at $40.0^{\circ} \mathrm{C}$ is 4.24 at Table 2 ) to isopropyl (1.09), suggesting that a value of less than unity would be observed upon incorporation of a bulky secondary alky group. This trend could possibly be governed by increasing steric effects.

In the present study, unlike the reactions in hydroxylic solvents of $n$-propyl chloroformate. where both the bimolecular pathway (Scheme 1) and the unimolecular pathway' 
(Scheme 2) were observed, the solvolyses of $n$-propyl fluoroformate all follow the pathway involving rate-determining bumolecular attack by solvent at acyl carbon.

\section{References}

1. Kyong. J. B.: Won. H.: Kevill. D. N. Int. J. Mot Sai 2005. 6. 87.

2. Kevill. D. N.: Kyong. J. B.: Weitl. F. L. J. Org. Chem. 1990. 55. 4304.

3. Kevill, D. N.: Kvong J. B. J. Org. Chem. 1992, 57.258.

4. Queen. A.; Nour. T. A. J. Chem. Soc. Perhin Trans. 21976.935.

5. Hudson. R. F.: Green. M. J. Chem. Soc. 1962. 1055.

6. Orlow S. I.: Chimishkyan. A. L.: Grabarnik. M. S. J. Org Chem. LSSR (Engl. Transt.) 1983. 19.1981.

7. Kevill, D. N.: D Souza, M. I. J. Chem. Soc. Perkin Trans. 2002. 240.

8. Kyong, I. B: Ryu, S. H; Kevill. D. N. Ift. J. Mol. Sci. $2006,7$. 186

9. (a) Grunwald. E.: Winstein. S. J. Ant Chent. Soc. 1948. 70. 846. (b) Winstein. S.: Grunwald. E.: Jones. H. W. J. Am. Chem. Soc. 1951, 73, 2700

10. Kevill. D. N. In Adnances in Quantitative Structure-Properth Relationships: Charton. M. Ed, JAI Press: Greenwich. CT, 1996; Vol 1.pp 81-115.

11. Kevill. D. N.: Anderson. S. W. J. Org Chem. 1991. 56.1845

12. (a) Schadt. F. L.: Bentley. T. W.: Schleyer. P. v. R. J. Am. Chem. Soc. 1976, 98, 7667. (b) Bentley, T. W. Llewellyn. G. Prog. Phns. Org. Chem. 1990, 17. 121.

13. (a) Bentlev: T. W. Carter. G. E. J. Am. Chem. Soc 1982. 104
5741. (b) Kevill, D. N.: DSouza. M. J. J. Chem Res., Synop 1993. 174. (c) Lomas. T. S.: D'Souza. M. J.: Kevill. D. N. J. Aint Chent Soc. 1995. 117.5891.

14. Kyong. J. B.; Park. B.-C ; Kim. C.-B.: Kevill. D. N. J. Org. Chem 2000. 65,8051

15. (a) Lorca, A. A.: Malfroot, T: Senet. J. P. Lnited States Patent Application Pub 2003.0120103Al. Tun. 26. (b) Culomo. T.: Olofson. R. A.J. Org. Chen. 1979. H. 1016.

16. Kyong. J. B.: Rhu. C. J.: Kiml. Y. G.: Kevill. D. N. J. Phss Org. Chem. 2007, 20,525.

17. Kevill, D. N.: Kim, J. C.: Kyong, J. B. J. Chem. Res., Synop. 1999. 150.

18. Kevill. D. N.: D'Souza. M. T. J. Org. Chent 1998. 63.2120.

19. Kevill. D. N.: D’Souza. M. J. J. Chem. Soc., Perkin Trams. 21997. 1721 .

20. Kevill, D. N.; Miller. B. J. Ong. Chem. 2002. 67.7399

21. Swain. C. G. Scott, C. B. J. Am. Chem. Soc. 1953. 75.246.

22. Song. B. D.: Jencks. W. P. J. Am. Chem. Soc. 1989, 111, 8470

23. (a) Wiberg. K. B.: Hadad. C. M.: Rablen1. P. R.: Cioslowski. J. J Ant Chent Soc. 1992. Ht. 8644. (b) Wiberg. K. B.: Rablen. P. R. J. Org. Chent 1998. 63. 3722.

24. Kevill, D. N.; DSouza. M. J. J. Org Chem 2004. 69,7044.

25. Lee. S. H.: Rhu, C. J; Kyong. J. B.: Kim, D. K.: Kevill. D. N. Bull. Korean Chem Soc. 2007, $28,657$.

26. Yew. K. H.: Koh. H. T.: Lee. H. W.: Lee. I. J. Chem. Soc, Perkin Trams. 2 1995. 2263.

27. Koo. I. S.: Yang. K.: Kang. K.: Lee. I. Bull. Korem Chem. Soc. 1998. 19,968

28. Kyong. J. B.: Kim, Y. G; Kim, D. K.: Kevill. D. N. Bull Koman Chem. Soc. 2000, 21. 662 . 